\title{
Review of PPP Model Provided by Public Service
}

\author{
Gui-hua Liü ${ }^{1, a}$, Meng Su ${ }^{2, b}$ \\ ${ }^{1,2}$ School of public affairs\&law, Southwest Jiaotong University, Chengdu, China,610036

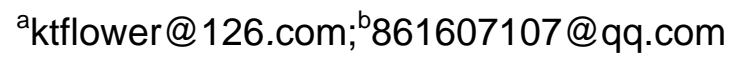

Keywords: PPP model; concept; efficiency; risk management; governmental responsibility

\begin{abstract}
The PPP model (Public-Private-Partnership) is recognized as a new way of providing public service. This model aims to cover the shortage of public departments and promote the efficiency of providing public service, through establishing the long-term cooperation between the public department and the private department by depending on the superiority of private department, including capital, technology and management methods. Recently, the PPP model has attracted great attention on the governments, and widely promoted in the field of public service. Also, it has become the hotspot in the academic field. On the basis of literatures, this paper is a review about the concept of PPP model, efficiency, risk management and the responsibility of governments. Finally, we propose our views on the development of PPP model in China.

PPP is the abbreviation of Public-Private-Partnership. In China, It means partnerships between the pubic and the private. The concept of public-private partnership was first carried out by Kenneth Clarke who was the British Chancellor of the Exchequer.[1]In 1984, Shenzhen B power plant in Sha Tou Jiao was constructed in BOT model, which was the sign of the PPP model in infrastructure. Then, it has also been promoted in transport, electricity, gas and other infrastructure fields. With the application of the PPP model in China, it has become a hot topic in academic, and has formed a lot of valuable results concentrated on the definition of PPP, the differences between PPP model and traditional model, the risk share mechanism and Government's responsibility. This paper is a summary of the PPP model that based on a lot of readings.
\end{abstract}

\section{Definition of PPP Model}

As the PPP model has been widely applied in the field of public service, scholars tend to treat the PPP model as an innovation rather than a financing mode. E S Savas(2002) explains PPP from three perspectives: firstly, viewing from the general perspective, the PPP model refers to any arrangement of public and private departments to jointly participating in the producing and providing public goods and services; secondly the PPP model refers to the infrastructure projects being complex, multi-participated and privatized; and thirdly the PPP model refers to the official cooperation among enterprises, social elites and governmental officials in order to optimize the condition of cities.[2] Viktorija Bojović(2006) regards the PPP model as a tool for changing the way of providing public service [3] Richard Hemming(2006) sees PPP as arrangement under which the private sector supplies infrastructure assets and infrastructure-based services that have traditionally been provided by the government.[4]According to Deng Xiao-peng, et al(2007) think that the PPP model is the cooperation mechanism between public and private departments, which is established in the form of contract, based on the risk sharing and benefit sharing for public department and private department to jointly provide public service. [5] Jia Kang and Sun Jie(2009) define the PPP model as the innovation of governmental management pattern, and point out the general functions (planning, organizing leading and controlling) and special functions (financing, innovating on the basis of techniques and mechanism) of the PPP model .[6]Wang Jun-hao and Fun Jin-cun (2014) regard PPP as an institutional innovation. They believe that the public-private-partnership is deemed as the long-term cooperation mechanism established with the basis of contract.[7]Therefore, there are some common characteristics: firstly, the participants of PPP model are the public and private departments; secondly, the purpose of PPP model is to provide better public service; thirdly, the partnership of the public and the private is based on contract. 


\section{Research of Efficiency of PPP Model}

\subsection{Comparative Study of Efficiency of PPP Model}

In the provision of public goods or services, there is a debate about whether the PPP model is more efficient than traditional model. Generally, it is believed that the PPP model has more advantages in capital, technology and management methods. So, in the previously researches, the PPP model is believed to be more efficient. With the application of the PPP model, some problems occurred. Therefore, the efficiency of PPP model raises scholars' attention. Milosavljevic M and Benkovic S(2009) point out some disadvantages of PPP:1. PPPs are relatively new concept that are not well understood in some countries.2.Limited competition is immanent to PPP projects due to high bidding costs.3. Political debates, complex negotiation processes and public opposition can cause delays in project implementation.4. Among the potential stumbling blocks to the successful implementation of PPPs is that the cost of capital to the private sector may be higher than to the public sector. Therefore, It is necessary to develop a hybrid model.[8]Hoppe E I and Schmitz $\mathrm{P}$ $\mathrm{W}(2012)$ believe that the process of providing public service can be divided as the building stage and the management and operation stage. When the government applies the PPP model, the two subdivided stages are undertaken by the same private department. In contrast, these two stages shall be in charged by different private departments under the traditional model. They also propose that under the mechanism of PPP, the social cost shall be added because of information collection [9] On the basis of game theory and the principal-agent theory, Zhang Hong-ming and Wang Ji-ying(2009) establish the game model between government and the private to show that the operation efficiency of PPP model shall be higher under the certain conditions.[10] Yao Dong-min and Li Jun-lin(2015) use the quantitative analytical method and based on VFM principle to compare the efficiencies of two models.[11] Wang Ying-ming(2016) analyze the inefficiency of PPP model .He points out that given the differences in target, negotiation ability, cost control and operation deadline between public and private departments, the inefficiency of PPP model shall be caused.[12]

\subsection{Factors of PPP Model Efficiency}

While PPP model is applied in the field of infrastructure and public service, its efficiency is bound by multiple factors. Skietrys, et al(2008) propose that the core factors of PPP efficiency are recognized as the requirement of the project, policy environment and the information communication between private and public departments.[13] Martimort D and Pouyet $\mathrm{J}(2008)$ believe that the externality of the project shall also exert influence to the efficiency of PPP model.[14] Lossa E and Martimort $\mathrm{D}(2008)$ point out that positive externality is the mainly factor of the PPP efficiency. [15]Zhang Zhe,et al (2009)think that the collocation of control right is recognized as the key factor for affecting PPP model efficiency.[16] Zhang Yu,et al(2012)divide the process of PPP model into four secondary processes from the perspective of incomplete contract theory, and analyze the factors of these processes respectively affecting the PPP model efficiency.[17] Ye Xiao-su and Qi Hai-mo(2015) categorize control right into three aspects which are system-supervision, contract management and the construction-operation. And factor analysis was used to analyze the influencing factors at all levels.[18]Therefore, the efficiency of PPP model is affected by various factors, the externality of project and the collocation of control right are the key factors.

\section{Risk Management of PPP Model}

\subsection{Risk Identification of PPP Model}

The researches of risk identification of PPP model conducted by scholars are mainly concentrated on the type of risks. Irem Dikmen Ozdoganm and M. Talat Birgonul(2000) generalize the risks based on the BOT project, namely are market risk, financial risk, political risk, legal risk, construction risk and operational risk.[19]Darrin Grimsey and Mervyn K. Lewis(2002) propose that there are 9 categories of risks existing in PPP model which are construction risk, operational risk, tax risk, technological risk, financial risk, risk of force majeure, political risk, environmental risk 
and the default risk of the project.[20]A. V. Thomas,et al(2003) analyze the BOT highway project in India, and categorized the risks from the perspective of project stage: formation stage risk, constriction stage risk, operation stage risk and project life cycle risk.[21]Qi Xia, et al(2009) point out that the main reason for the failure of the project is the risk of the project and categorize the risks into 13 types. [22] Wu Jin(2013) divides the risks existing in the PPP model into the external risk and the internal risk..[23]Deng Xiong(2015) believes there are five categories of risks existing in the PPP model: legal risk, long examination and approval cycle, political risk, risk of governmental default, and risk of project returns missing the anticipation.[24]In short, scholars have classified the risks of PPP projects from different perspectives. According to these risks, the characteristics of PPP risks can be concluded, such as subjectivity and particularity.

\subsection{Risk Assessment of PPP Model}

Songer A D,etc(1997) point out that the Monte Carlo Method is recognized as an effective method for risk assessment.[25]The Scenario Analysis method is adapted by Rodney W and Gallimore P(2002) to assess the risk of PPP model.[26] Grimsey D and Lewis M K (2005) apply the PSC model to confirm whether the PPP project contains good value for money (VFM).[27]Feng Yan(2007) calls for the application of quantization method to assess the risk of PPP model..[28] On the basis of Markowitz model, Yang Qiu-bo and Hou Xiao-wen(2008) propose the mathematic model for risk sharing.[29] The sensitivity of risk factors in PPP model is demonstrated by Han Ya-pin and Jiang Gen-mou(2009) use the sensitivity analysis method and the probability analysis method to calculate the probability of risk factors.[30] Li li (2012) uses the risk matrix to determine the level of each risk, and secondly, the Borda sequence value method is used to quantify the risk factors. [31] In a word, risk assessment is an important part in risk management, and it is beneficial to allocate risk to participants in PPP projects.

\subsection{Risk Sharing of PPP Model}

For the risk sharing of PPP projects, the research mainly focuses on the following aspects: The first is the discussion on the sharing party. Most of scholars in China think that the sharing parties are public and private sectors. Arndt R H (1998) believes that the sharing part also includes the user of public service.[32] So the main sharing parties include not only the public and private sectors but also the users. In addition, some scholars have put forward the requirements of risk sharing parties, such as Ng and Martin Loos (2007), which believe that the requirements are: firstly, fully aware of the risks they will take; secondly, have the ability to undertake; thirdly, have the ability and resources to deal with the sustainability of risks; fourthly, there is a necessary risk appetite for risk taking; finally, there is the opportunity to claim the costs incurred by taking risks. [33] The second is to discuss the principle of sharing. Scholars have formed a consensus view of about the principles, such as Li Li-hong, Zhu Bai-feng(2014) [34], Tao Si-ping(2015) [35], Deng Xiong(2015),et al[24]. They think that there are three main principles: the ability to share the risks is related to the ability to control; risk sharing matches the benefits; and the dynamic principle of risk sharing. The third is the discussion of the sharing results. Li Bing etc. (2005) believe that the public sector is more efficient than the private sector for macro risks. [36] Li Li-hong and Zhu Bai-feng(2014) believe that the public sector has an advantage in undertaking political risks and legal risks; the private sector tends to undertake the risk of construction and operational risk; economic risk and natural risk are assumed by both parties. [34] The last is the discussion of risk re-sharing. Risk re-sharing refers to an adjusted process of risk sharing, which due to the occurrence of risk events, and public sector or private sector is dissatisfied with the initial risk allocation. At present, there are two main opinions about risk re-sharing: on the one hand, some scholars believe that risk re-sharing is an opportunistic method; on the other hand, some think that it is actually a remedy for the injured party in the project. [37] In a word, the studies show that the current research on risk sharing is mainly the initial sharing of risk, while the research on risk re-sharing is less. 


\section{Governmental Responsibility of PPP Model}

Kumaraswamy M M ,et al(2001) point out that there are two major responsibilities of government, firstly attracting the fund effectively for infrastructure construction, secondly guaranteeing the effective application of private fund and the realization of public interest.[38] Doh J P and Ramamurti R(2003) analyze the role of government, and they believe that the government is the initiator, the consumer, as well as the rule maker.[39] Hedley Smyth and Andrew Edkins(2006) propose that the most important responsibility of the government is to hold the integrity. [40] Liu $\mathrm{Yu}(2009)$ analyze the responsibilities of government in each stage, and proposes that government has different roles in different stages.[41] $\mathrm{Xu}$ Xia,et al(2009) raise that the responsibility of government is to supervise.[42] Chen Wan-ling(2014) analyzes the governmental responsibility of PPP from three perspectives: firstly, on the PPP legislation, government shall improve the relevant laws and regulations; secondly, on the contact of PPP, government shall introduce the competitive negotiation and guarantee the transparency of PPP project; thirdly, on the supervision of PPP, government shall guarantee the independent supervision cored by public interest. [43]Therefore, the government shall play an importance role in formulating the rules, attracting investment and risk management, and also hold the integrity. establish the independent supervision department as to prevent the private department from rent-seeking.

\section{Conclusion}

The application of PPP model in public service has been accepted among the academic field, and has achieved a positive effect in practice. Currently, China is in the period of comprehensively deepening reform, and the aim is to promote the governance system and the governance capacity. For this reason, it is extremely necessary to gain the power from all participates to take part in the national governance. PPP model is perceived as the typical model on the basis of the long-term cooperation between public and private departments aiming at infrastructure construction and providing public goods and services. At present, the concept of PPP model has been relatively clarified among the academic field, and has done many researches on risk management. In the mean time, scholars have also studied the responsibility of government. With the promotion of PPP model, some of PPP projects have not achieved the desired effect. Therewith, the efficiency of PPP model has been reevaluated by scholars. According to the research results, PPP model is not always efficient, and only if some certain requirements are met, can the PPP model exert positive influence. Finally, some of scholars have been aware of using quantitative method to analyze the risks of PPP model. According to the literature review, the focus is to establish a mathematical model to analyze the risks and benefits, so as to coordinate the relationship between the public departments and the private departments.

\section{References}

[1] Ye Xiao-su,Xu Chun-mei.Review and research on PPP Pattern in China[J].Soft Science,2013,06:6-9. (in Chinese)

[2] E·S·Savas.Privatization and Public-Private Partnership[M]Beijing:China Renmin University Press, 2002.

[3] Viktorija Bojović. Public private partnership as a last resort for traditional public procurement[J]. Panoeconomicus,2006,53(3):299-311.

[4] Hemming,R.,2006. "Public-Private Partnerships, government guarantees, and fiscal risk", International Monetary Fund.

[5] DENG Xiao-peng,LI Qi-ming,SHEN Li-yin.Interpretation of characters and related conceptions for PPP model in urban public projects[J]. Modern Urban 
Research,2007,01:29-33.(in Chinese)

[6] JIA Kang,SUN Jie. The concept, origin, characteristics and function of public - private partnership (PPP) [J]. Financial research,2009,10:2-10.(in Chinese)

[7] WANG Jun-hao,FU Jin-cun. The Essential Characteristics of Public-private Partnerships and Policy Selections of Chinese City Public Utilities [J]. China Industrial Economics,2014,07:96-108.(in Chinese)

[8] Milosavljevic M, Benkovic S. Modern aspects of public private partnership[J]. Perspectives of Innovations Economics \& Business, 2009, 3(3):25-28.

[9] Hoppe E I, Schmitz P W. Public, rivate partnerships versus traditional procurement: Innovation incentives and information gathering $[\mathrm{J}]$. Rand Journal of Economics, 2012, 44(1):56-74.

[10]ZHANG Hong-ming,WANG Ji-ying. A Comparative Study on the Operational Efficiency [J]. Northern Economy,2009,04:18-20. (in Chinese)

[11]YAO Dong-ming;LI Jun-lin. The Efficiency Difference under the Condition Satisfying: Comparison of PPPModel and Traditional Model [J]. Reform,2015,02:34-42.(in Chinese)

[12]WANG Ying-ming. Research on Non-efficiency of PPP Model in Public Service Provision [J].Knowledge economy,2016,15:36-37. (in Chinese)

[13] Skietrys E, Raipa A, Bartkus E V. Dimensions of the efficiency of public-private partnership [J] . Engineering Economics, 2008, 58 (3) : 45-50.

[14]Martimort D, Pouyet J. To build or not to build: Normative and positive theories of public-private partnerships [J].International Journal of Industrial Organization, 2008, 26(2):393-411.

[15]Lossa E, Martimort D. The Simple Micro-Economics of Public-Private Partnerships[C] Department of Economics, University of Bristol, UK, 2008:4-48.

[16]ZHANG Zhe,JIA Ming,WAN Di-fang. Theoretical Study on the Efficient Allocation of Control Rightsin the Public-Private Partnership (PPP) [J]. Journal of Industrial Engineering Management,2009,03:23-29+22.(in Chinese)

[17]ZHANG Yu,XU Wen-long,ZHANG Xiao-fen. An Analysis on the Influencing Factors of PPP Efficiency from the Perspective of Incomplete Contract [J]. Theory Monthly,2012,12:103-107. (in Chinese)

[18]YE Xiao-su,QI Hai-mo. A Study on the Key Influencing Factors of Cooperative Efficiency of PPP Project - Based on the View of Control rights [J]. PROJECT MANAGEMENT TECHNOLOGY,2015,04:9-14.(in Chinese)

[19]Irem Dikmen Ozdoganm, M. Talat Birgonul. A decision support framework for project sponsors in the planning stage of build-operate-tran sfer (BOT) projects[J]. Construction Management \& Economics, 2000, 18(3):343-353.

[20]Grimsey D, Lewis M K. Evaluating the risks of public private partnerships for infrastructure projects[J]. International Journal of Project Management, 2002, 20(2):107-118.

[21]A. V. Thomas, Satyanarayana N. Kalidindi, K. Ananthanarayanan. Risk perception analysis of BOT road project participants in India[J]. Construction Management \& Economics, 2003, 21(4):393-407.

[22]QI Xia,KE Yong-jian,WANG Shou-qing. Analysis on CriticalRisk Factors Causing the Failures 
ofChina.s PPP Projects [J]. China Soft Science,2009,05:107-113. (in Chinese)

[23]WU Jin.Research on risk sharing of Infrastructure PPP project financing model.[D].Dongbei University of Finance \&Economics,2013. (in Chinese)

[24]DENG Xiong. Analysis of Risk and Risk Sharing Mechanism of PPP Model [J].Internantional Finance,2015,10:75-80.(in Chinese)

[25] Songer A D, Diekmann J, Pecsok R S. Risk analysis for revenue dependent infrastructure projects[J]. Construction Management \& Economics, 1997, 15(4):377-382.

[26]Rodney W, Gallimore P. Risk assessment in PFI schemes for primary health care[J]. Facilities, 2002, 20(1/2):52-60.

[27] Grimsey D, Lewis M K.Are public private partnership value for money?[J].Accounting Forum, 2005:345-378.

[28]FENG Yan. Research on the Risk Identification and Quantitative Risk Analysis of a PPP Project

[29]Financing Mode [D]. Chongqing University,2007.(in Chinese)

[30] YANG Qiu-bo,HOU Xiao-wen. Research on the Improvement of PPP Risk Sharing Framework [J].Project Management technology,2008,08:13-17. (in Chinese)

[31]HAN Ya -pin, JIANG Gen -mou. Sensitivity Analysis and Its Improvement in the Application of PPP Projects' Risk Evaluation [J]. Water Conservancy Science and Technology and Economy,2009,01:1-3. (in Chinese)

[32]LI Li. The Risk Assessment of BOT - TOT - PPP Project Financing Based on Risk Matrix [J]. Journal of Kunming University of Science and Technology,2012,01:74-79. (in Chinese)

[33] Arndt R H. Risk Allocation in the Melbourne City Link Project[J]. Journal of Structured Finance, 1998, 4(3):11-24.

$[34] \mathrm{Ng} A$, Loosemore $\mathrm{M}$. Risk allocation in the private provision of public infrastructure[J].International Journal of Project Management,2007, 25(1):66-76.

[35]LI Li-hong,ZHU Bai-feng,LIU Ya-chen. Research on Risk Sharing Mechanism of Integrated Framework for PPP Pattern [J].Construction Economy,2014,09:11-14. (in Chinese)

[36]TAO Si-ping. Research on Risk Sharing of PPP Model - Based on the Analysis of Beijing Rail Transit [J]. Modernization of Management,2015,04:85-87.(in Chinese)

[37]Li Bing,A Akintoye,P J Edwards. The allocation of risk in PPP/PFI construction projects in the UK[J].International Journal of Project Management,2005,23(1):25-35.

[38]HUANG Heng-zhen, ZHOU Guo-hua. Study on the risk resharing of PPP project.[J] Construction Economics, 2015,(10):17-20.(in Chinese)

[39]Kumaraswamy M M, Zhang X Q. Governmental role in BOT-led infrastructure development[J]. International Journal of Project Management, 2001, 19(4):195-205.

[40]Doh J P, Ramamurti R. REASSESSING RISK IN DEVELOPING COUNTRY INFRASTRUCTURE[J]. Long Range Planning, 2003, 36(4):337-353.

[41]Hedley Smyth,Andrew Edkins.Relationship management in the management of PFI/PPP projects in the UK.International Journal of Project Management.2007:232-240.

[42]LIU Yu.Research on the government responsibility in the city infrastructure PPP project[D].Southwest Jiaotong University,2010. (in Chinese) 
[43]XU Xia,ZHENG Zhi-ling,ZHOU Song. Research on Government Supervision System under PPP Model[J]. Construction Economics， 2009.07:105-108. (in Chinese)

[44]CHEN Wan-ling.Origins, Valueand Government Responsibilities of Public-private Partnership[J].Journal of Shanghai University of Finance and Economics,2014,05:75-83.(in Chinese) 